\title{
Streit um Italiens Haushalt
}

Seit Juni ist die neue italienische Regierung um Ministerpräsident Giuseppe Conte im Amt. Getragen wird sie von der rechtspopulistischen Lega Nord und der linkspopulistischen „Fünf Sterne“-Bewegung, die im Süden des Landes verankert ist. Und diese Regierung will 2019 nun deutlich mehr Geld ausgeben als von ihren Vorgängern anvisiert. Sie plant Mehrausgaben von 34 Mrd. Euro, von denen 22 Mrd. Euro über Neuverschuldung finanziert werden sollen. Konkret geht es um die Rücknahme einer bereits beschlossenen Mehrwertsteuererhöhung (12 Mrd. Euro), ein Grundeinkommen für Langzeitarbeitslose (7 Mrd. Euro), eine Frühverrentungsinitiative (7 Mrd. Euro) und einige kleinere Posten. Das Budgetdefizit würde damit rund 2,4 \% des Bruttoinlandsprodukts (BIP) betragen. In den Folgejahren sind dann Defizite von 2,1\% und 1,8\% geplant. Damit bliebe Italien zwar unterhalb der 3\%-Grenze der Maastricht-Kriterien. Aber die Gesamtverschuldung liegt schon jetzt bei $130 \%$, dem zweithöchsten Wert in der Eurozone nach Griechenland, und damit weit oberhalb der vorgeschriebenen $60 \%$. Außerdem würde Italien im kommenden Jahr nach den gängigen (aber umstrittenen) Verfahren der Konjunkturbereinigung beim strukturellen Defizit 0,8 Prozentpunkte zulegen.

Beides steht im Widerspruch zum Stabilitäts- und Wachstumspakt (SWP) und den dort vorgezeichneten Anpassungspfaden. Deshalb hatte die Europäische Kommission kaum eine Wahl, als den italienischen Budgetentwurf im Rahmen des präventiven Arms des SWP formal zurückzuweisen. Dies geschah zum ersten Mal seit Bestehen der gesetzlichen Grundlagen. Die EU-Kommission gab Rom in ihrem blauen Brief drei Wochen Zeit, um den Budgetentwurf zu überarbeiten. Aber der neue starke Mann der Regierung, Innenminister Matteo Salvini, antwortete prompt: Italien denke gar nicht daran, Änderungen vorzunehmen oder sich von Brüssel Vorschriften machen zu lassen. Da scheinen also zwei Züge in voller Geschwindigkeit aufeinander zu zurasen.

Diese Dramatik verkennt, dass Roms eigentlicher Konflikt nicht mit Brüssel, sondern mit den Finanzmärkten besteht. In letzter Konsequenz hat die EU-Kommission kaum einen Einfluss auf die italienische Haushaltsführung. Zunächst kann Brüssel bloß Ratschläge erteilen. Sanktionen im Rahmen des korrektiven Arms des SWP könnten erst im nächsten Jahr und vermutlich erst nach den Europawahlen folgen, wenn Rom den Entwurf umsetzt. Ob solche Sanktionen tatsächlich kommen, ist durchaus fraglich. Denn die zu exekutierenden Fiskalregeln stehen ihrerseits in der Kritik und sind Gegenstand einer grundsätzlichen Reformdiskussion. Viele Länder (darunter Deutschland) verstießen oder verstoßen dagegen. Es wäre also merkwürdig, wenn nur Italien bestraft würde. Viel wichtiger sind für Rom ohnehin die berühmten Spreads. Der Zinsabstand zwischen zehnjährigen deutschen und italienischen Anleihen beträgt schon jetzt rund 300 Basispunkte. Dieser Aufwuchs ist nicht bloß eine Reaktion auf den Haushaltsentwurf. Noch wichtiger war wohl Salvinis öffentliches Nachdenken über einen Euro-Austritt seines Landes. Die Unsicherheit darüber ist weiterhin im Markt, auch wenn Ministerpräsident Conte seither versucht, diese Gedankenspiele zu beenden.

Zwar hängt Italien nicht akut an der Nadel internationaler Kapitalgeber. Rom hat die aktuelle Niedrigzinsphase zur Umschuldung und Fristverlängerung seiner Anleihen genutzt. Die jährlichen Zinszahlungen machen heute nur rund $8 \%$ des BIP aus, nicht viel mehr als in Spanien oder Großbritannien. Und überhaupt sind die Gläubiger des italienischen Staates in der großen Mehrzahl Inländer und italienische Banken. Es droht also - anders als im Fall Griechenlands während der Eurokrise - kein akuter

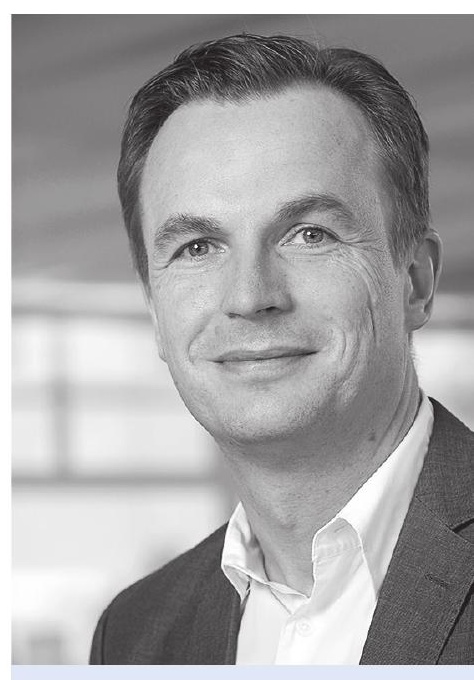

Jens Südekum ist Professor am Düsseldorf Institute for Competition Economics (DICE). 
Zahlungsausfall gegenüber ausländischen Gläubigern. Aber Salvini hat zugegeben, dass steigende Spreads ein Problem darstellen. Angeblich ließ er verlauten, dass er ab 400 Basispunkten beginne, nervös zu werden. Zudem erhöhen steigende Zinsen beim Staat tendenziell die Finanzierungskosten italienischer Unternehmen, wie Olivier Blanchard und Jeromin Zettelmeyer kürzlich argumentierten, und belasten damit die Volkswirtschaft zusätzlich.

Brüssels wesentlicher Hebel auf Rom ist also keine fiskalische Sanktion. Er besteht in einem Zinsauftrieb, der durch eine weitere Eskalation der Auseinandersetzung entstehen könnte. Kann Europa daran ein Interesse haben? Viele in Deutschland würden wohl zustimmen. Sie erleben den italienischen Haushaltsentwurf als einen Akt der Erpressung. Rom wisse schließlich, dass der Rest der Gemeinschaft im Ernstfall wenn Italiens Banken bei einem Kursverfall ihrer Anleihebestände in eine Schieflage gerieten - einspringen müsste, um die eigenen Banken zu retten. Weil Italien letztlich „too big to fail“ sei, müsse die Regierung zur Räson gebracht werden. Aber sollte sich Europa wirklich in die Rolle eines Erpressungsopfers zurückziehen? Wie furchteinflößend ist überhaupt ein italienischer Erpresser, der sich durch den Vollzug seiner angeblich erpresserischen Handlung (steigende Verschuldung, Zahlungsausfälle, im Extremfall ein Italiexit) zu allererst selbst schadet? Kaum vorstellbar, dass Salvinis Wähler - zumal im wirtschaftsstarken Norditalien - einem solchen Spiel lange zuschauen würden. Zwar schätzen sie seine unnachgiebige Haltung in der Migrationsfrage. Aber sie haben kein Interesse an einem wirtschaftlichen Ruin ihres Landes.

Europa täte besser daran, konstruktiv auf die italienische Position einzugehen und dem Land bei seinem größten Problem zu helfen: zehn Jahre ohne Wirtschaftswachstum. Von Beginn der 1990er Jahre bis zur Finanzkrise ist Italien genauso schnell gewachsen wie Deutschland. Aber 2008 hörte das abrupt auf. Seitdem kämpft vor allem der Süden mit massiver (Jugend-)Arbeitslosigkeit, die in einigen Regionen bei über $50 \%$ liegt und verlorene Generationen hervorgebracht hat. Europas Austeritätspolitik ist dafür zumindest mitverantwortlich. Während der gesamten Zeit hat Italien aber eine konservative Haushaltsführung praktiziert und permanente Primärüberschüsse gebildet. Abzüglich der Zinszahlungen auf den riesigen Altschuldenbestand, der vor allem in den 1970er und 1980er Jahren angehäuft wurde, haben italienische Regierungen seit über zwanzig Jahren nicht mehr über ihre Verhältnisse gelebt. Sogar einen Exportüberschuss weist das Land auf.

Das Rezept für mehr Wachstum besteht also sicher nicht aus „schmerzhaften Anpassungen“ zur Wiederherstellung von Wettbewerbsfähigkeit. Aber es besteht auch nicht in sinnlosen Ausgabenprogrammen ohne nennenswerten langfristigen Effekt. Nach Einschätzung vieler internationaler Beobachter fallen die Frühverrentungs- und Grundeinkommensprogramme, die maßgeblich von der „Fünf Sterne“-Bewegung geprägt sind, genau in diese Kategorie. Wenn der fiskalische Stimulus aber verpufft und von weiter steigenden Spreads aufgefressen wird, dann bekommt Italien nicht mehr Wachstum, sondern bloß noch mehr Schulden. Die Herausforderung wird also darin bestehen, mehr Geld an der richtigen Stelle auszugegeben und die Märkte zu überzeugen, dass tatsächlich Wachstumsimpulse gesetzt werden. Wo die richtige Stelle ist - im Bildungssystem, bei der Infrastruktur, beim Zugang zu Risikokapital für junge Unternehmen - muss letztlich die Regierung Conte entscheiden. Aber Europa kann sie dabei beraten und unterstützen, während man parallel an einer Runderneuerung des Regelwerks der Eurozone arbeitet und nicht auf der Einhaltung von ohnehin obsoleten Fiskalvorschriften besteht.

Jens Südekum

DICE

suedekum@dice.uni-duesseldorf.de
Vor allem sollte Europa zur Beruhigung der Finanzmärkte beitragen. Denn in letzter Konsequenz steht wieder einmal die Zukunft des Euro auf dem Spiel. 